\title{
Formate-Free Metal-Organic Decomposition Inks of Copper Particles and Self-Reductive Copper Complex for the Fabrication of Conductive Copper Films
}

\author{
Yuki Kawaguchi, Ryuichi Arakawa and Hideya Kawasaki ${ }^{*}$ \\ Faculty of Chemistry, Materials and Bioengineering, Kansai University, 3-3-35 Yamate-cho, Suita 564-8680, Japan
}

\begin{abstract}
Metal-organic decomposition (MOD) inks have been developed for printed electronics applications. Cu-based MOD inks prevent the oxidation of the metal during storage, as the $\mathrm{Cu}$ is already present in an oxidized form (i.e. a salt). However, usually hazardous formates such as $\mathrm{Cu}$ (II) formate have to be used as the copper salt in order to ensure thermal decomposition and self-reduction of the metal salt at moderate temperatures (less than $150{ }^{\circ} \mathrm{C}$ ). In this study, a formate-free hybrid ink containing copper particles and a Cu/1-amino-2-propanol (AmIP)/acetate complex was developed for the fabrication of conductive copper films on flexible polymer substrates at low sintering temperatures. A hybrid ink with a weight ratio of 3:1copper particles to MOD ink produced a conductive copper film with close-packed copper particles and a low resistance of $7.3 \times 10^{-5} \Omega \mathrm{cm}$ after sintering at a temperature of $180^{\circ} \mathrm{C}$ for 60 min under a $\mathrm{N}_{2}$ gas flow. Good oxidation resistance of the copper films was observed after exposure to air at $23^{\circ} \mathrm{C}$ for two months.
\end{abstract}

Received on 11-07-2016 Accepted on 03-10-2016 Published on 13-10-2016

Keywords: Metal-organic decomposition ink, Electrical conductivity, Sintering.

DOI: http://dx.doi.org/10.6000/2369-3355.2016.03.02.2

\section{INTRODUCTION}

Copper-based conductive inks are of great interest for printed electronics, due to their high conductivity, low cost, and reduced electro-migration effect. Usually, two main types of ink are used, metal nanoparticle-based inks and metalorganic decomposition (MOD) inks [1, 2]. A major challenge for copper-based inks is the very rapid oxidation rate in air, during storage and sintering (essential for obtaining conductive percolation paths). To avoid the oxidation of copper in the sintering process, a reducing gas, such as hydrogen, is typically introduced to supress the oxidation during the sintering process, and the reduction temperature should be higher than $230^{\circ} \mathrm{C}$ when hydrogen is used in order to achive the enhanced reducing aibility $[3,4]$.

MOD copper inks enable us to overcome the oxidation of copper during storage, since the metal is already present in its oxidized form (i.e. Cu (II) salt). In most cases, Cu (II) formate is used in the MOD inks from the benefit of formate: low thermal decomposition of $\mathrm{Cu}$ (II) formate at moderate temperatures (less than $150{ }^{\circ} \mathrm{C}$ ) and the self-reduction reaction ability of the $\mathrm{Cu}$ (II) salt by the formate [5-13].

"Faculty of Chemistry, Materials and Bioengineering, Kansai University, 3-3-35 Yamate-cho, Suita 564-8680, Japan; Tel: 81-6-6368-0979;

E-mail: hkawa@kansai-u.ac.jp
However, there are stains and corrosion problems caused by formic acid vapor as strong acid during the sintering process. Thus, alternative MOD inks based on copper carboxylate have been developed from the view point of being formate free to achieve adequately conductive copper films, although the sintering temperatures are relatively high (above $250{ }^{\circ} \mathrm{C}$ ) [14]. Another issue in MOD copper inks is the low Cu content (typically $20 \mathrm{wt} \%$ ) in the ink compared to the Cu nanoparticlebased ink (more than $40 \mathrm{wt} \%$ ). In order to ensure a sufficiently high copper content, the effectiveness of hybrid MOD ink with copper particles has been demonstrated for fabricating conductive copper films $\left(\sim 9 \times 10^{-4} \Omega \mathrm{cm}\right)$ at $100{ }^{\circ} \mathrm{C}$ [15]. Previously, we have demonstrated that 1-amino-2propanol (AmIP) has reduction abilities in a copper nanoparticle-based ink [16]. Hence, AmIP is expected to be appropriate for replacing formate in MOD inks due to the selfreduction reaction ability of the $\mathrm{Cu}$ (II) salt [16].

In this study, we present a formate-free hybrid MOD ink containing copper particles and $\mathrm{Cu}$ (II)/AmIP/acetate complex for the fabrication of conductive copper films on flexible polymer substrates. The $\mathrm{Cu}$ particles are inter-connected via the thermal decomposition of the complex at low temperatures between 120 and $140{ }^{\circ} \mathrm{C}$, compared to the case (above $250^{\circ} \mathrm{C}$ ) of $\mathrm{Cu}$ (II) acetate. As a result, the hybrid ink produced a conductive copper film with a low resistance 
of $\sim 7 \times 10^{-5} \Omega \mathrm{cm}$ after sintering at a temperature of $180{ }^{\circ} \mathrm{C}$ under a $\mathrm{N}_{2}$ gas flow without reducing gas such as hydrogen and formic acid.

\section{MATERIAL AND METHODS}

Polyimide (PI) films with a thickness of $50 \mu \mathrm{m}$ and high thermal resistance were used as flexible substrates for the $\mathrm{Cu}$ films. All the chemicals were used as received without further purification. 1-amino-2-propanol (AmIP, 98\%), ethylene glycol (99.5\%), and methanol (99.5\%) were purchased from Wako Chemicals, Japan. Copper particles (1 5 $\mu \mathrm{m})$ were purchased from Kojundo Chemical Laboratory Co., Ltd, Japan. A Cu (II)/AmIP/acetate complex was prepared by mixing $\mathrm{Cu}$ (II) acetate $(3 \mathrm{~g})$ and $\mathrm{AmIP}(2.6 \mathrm{~mL})$ in a mixed solvent of methanol $(7 \mathrm{~mL})$ and ethylene glycol $(0.67$ $\mathrm{mL}$ ) at ice bath. The resultant solution was stirred for $2 \mathrm{~h}$. The free acetic acid and the residual methanol were removed by drying under vacuum for $1 \mathrm{~h}$ at $50^{\circ} \mathrm{C}$ and then for $3 \mathrm{~h}$ at room temperature under vacuum, resulting in a MOD ink. To ensure a high copper content, a hybrid MOD ink was prepared by stirring the MOD ink with copper particles (1 5 $\mu \mathrm{m})$ in mortar under air for about 30 min until they turn into paste. Before the mixing the copper particles with the MOD ink, where the copper particles were immersed in N,N-diethyl hydroxylamine, and then copper particles were washed with AmIP, toluene, and hexane. The prolonged de-solvent process for the hybrid MOD ink under high vacuum should be avoided due to the risk of elimination of ethylene glycol from the ink, resulting in the aggregation of copper particles. In this case, a few drops of ethylene glycol( $\sim 10 \mu \mathrm{L})$ into the MOD ink could produce paste-like hybrid MOD ink by re-dispersion of copper particles.

We prepared hybrid MOD inks with different weight ratios of copper particles to Cu:MOD ink $=3: 1$ (0.3:0.1 g), $2: 1$ (0.27:0.13 g), 1:1(0.2:0.2 g), and 1:2 (0.13:0.27 g). The hybrid MOD ink was deposited into wiring gutter on a polyimide film using a doctor blade method. The resulting $\mathrm{Cu}$ films were then sintered at various temperatures for $60 \mathrm{~min}$ in an electric furnace (FT-6000, FuLL-TECH, and Osaka, Japan) under a $\mathrm{N}_{2}$ gas flow of $1.1 \mathrm{~L} / \mathrm{min}$. The thickness of each $\mathrm{Cu}$ film after heating $(\sim 80 \mu \mathrm{m})$ was determined using a surface roughness measurement tool (SJ 310, Mitutoyo, Japan). The electrical resistivity of the $\mathrm{Cu}$ conductive films was analyzed using a four-point probe instrument (Loresta AX MCP-T370, Mitsubishi Chemical Analytech Co., Japan) from the measured values of the sheet resistance and the thickness of Cu film.

Field-emission scanning electron microscopy (FE-SEM; JSM6700 , JEOL, Japan) images were collected at an acceleration voltage of $5.0 \mathrm{kV}$. X-ray diffraction (XRD) patterns were obtained using a diffractometer (D2 Phaser, Bruker, Germany) with a $\mathrm{Cu}-\mathrm{K}_{\alpha}$ radiation source $(\lambda=1.5406 \AA)$. Thermo-gravimetric analysis (TGA) was performed using a TG analyser (Thermo plus EVO, Rigaku, Japan) at a heating rate of $10^{\circ} \mathrm{C} / \mathrm{min}$ under a nitrogen flow.

\section{RESULTS AND DISCUSSION}

FT-IR spectrum of $\mathrm{Cu}$ (II)/AmIP/acetate complex is shown in Figure 1a. The $\mathrm{O}-\mathrm{H}$ stretching and $\mathrm{N}-\mathrm{H}$ stretching bands were observed 3255 and $3067 \mathrm{~cm}^{-1}$ for the complex, respectively, which are originated from the AmIP ligands in the complex. In addition, the symmetric and antisymmetric carboxylate stretch modes (1405 and $1560 \mathrm{~cm}^{-1}$ ) were also observed in the complex, indicating that the complex also includes the coordination of acetate to the $\mathrm{Cu}$ (II). The thermogravimetric analysis of the $\mathrm{Cu}$ (II)/AmIP/acetate complex under a nitrogen flow is shown in Figure $\mathbf{1 b}$. The total content of $\mathrm{Cu}$ in the complex was estimated approximately to be $22 \pm 3.5$ wt\% from the weight loss in the TG curve, which is close to the theoretical value (19.3 wt \%) of $\mathrm{Cu}$ (II)/AmIP/acetate complex with a molar ratio of $1: 2: 2[\mathrm{Cu}$ (II):AmIP:acetate]. This estimation is based on the fact that the weight loss in the TG curve is attributed to the decomposition/ volatilization of ligands in the complex. That is, the residue at high temperature $\left(\sim 400^{\circ} \mathrm{C}\right)$ can be regarded as copper. From the FT-IR and TG-DTA data, it is likely that the copper complex
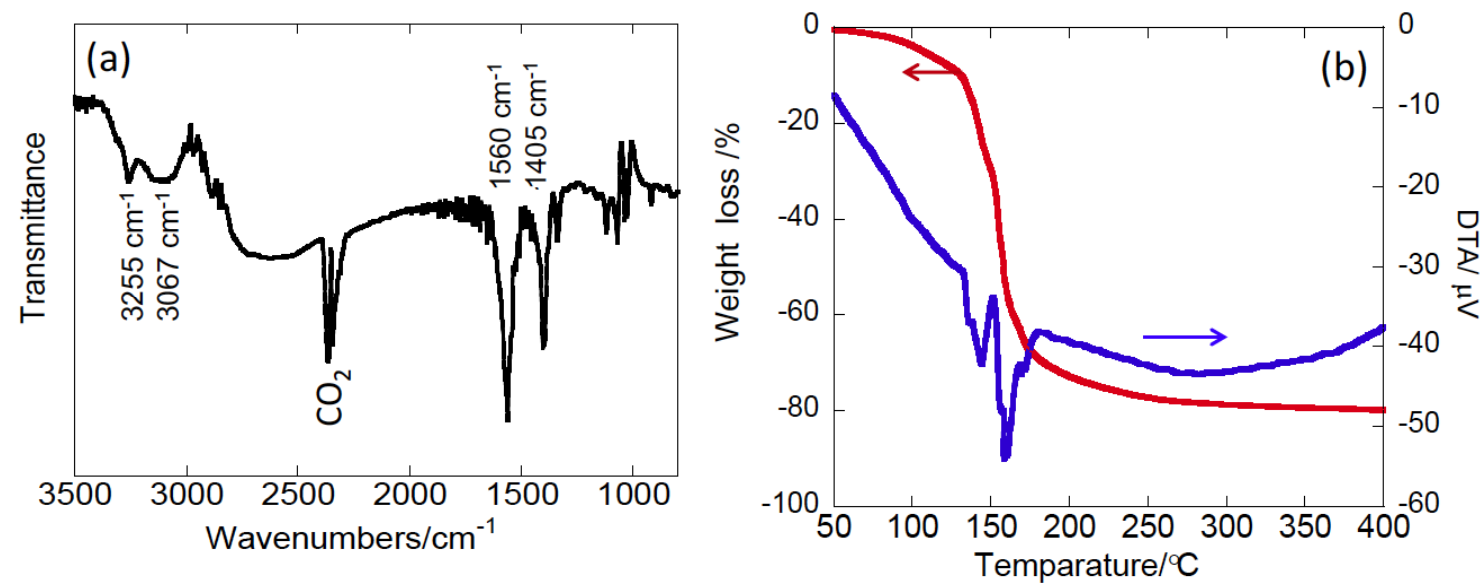

Figure 1: (a). FT-IR spectrum of Cu(II)-AmIP-acetate complex with a molar ratio of 1:2:2 (Cu(II):AmIP:acetate). (b) TG-DTA curves of the Cu(II)AmIP-acetate complex at a heating rate of $10^{\circ} \mathrm{C} / \mathrm{min}$ under a $\mathrm{N}_{2}$ flow. 
(a)

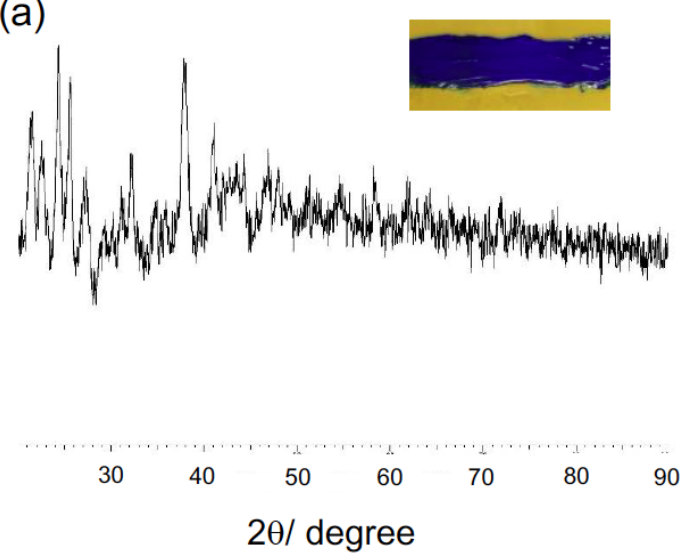

(b)

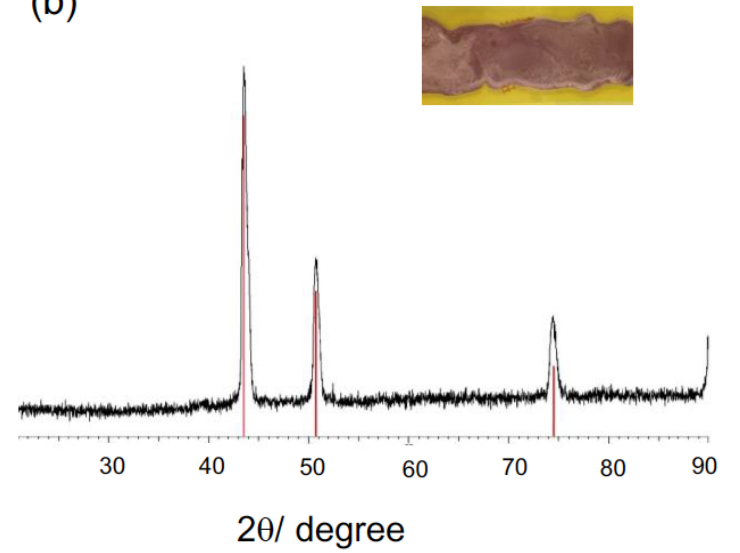

Figure 2: XRD pattern of (a) MOD ink with Cu(II)-AmIP-acetate complex with a molar ratio of 1:2:2 (Cu(II):AmIP:acetate) and (b) copper film achieved after calcination of the MOD ink at $150{ }^{\circ} \mathrm{C}$ for $30 \mathrm{~min}$. The insets are photographs of the MOD ink (a) and the copper film on a polyimide substrate (b).

prepared in this study is $\mathrm{Cu}(\mathrm{II}) / \mathrm{AmIP} /$ acetate complex $(1: 2: 2)$.

It should be noted that the thermal decomposition of the $\mathrm{Cu}(\mathrm{II}) / \mathrm{AmIP} / \mathrm{acetate}$ complex occurred at low temperatures between 120 and $140{ }^{\circ} \mathrm{C}$ in the TG curves, which is much lower than that $\left(>250{ }^{\circ} \mathrm{C}\right)$ of $\mathrm{Cu}(\mathrm{II})$ acetate complex [17]. It has been reported that the coordination of amine to $\mathrm{Cu}$ (II) reduces the thermal decomposition temperature [8, 9]. The reduction of thermal decomposition temperature of the $\mathrm{Cu}$ (II)-AmIP-Ac complex is attributed to the coordination of AmIP to $\mathrm{Cu}$ (II).

The XRD analysis of MOD ink containing the $\mathrm{Cu}$ (II)/AmIP/acetate complex showed no diffraction peaks of metallic copper before the heating, while the thermal decomposition of MOD ink by the heating of $150{ }^{\circ} \mathrm{C}$ for 30 min under a $\mathrm{N}_{2}$ gas produced metallic $\mathrm{Cu}$, which was identified by its diffraction peak (Figure 2). There was no observation of the oxidation of copper in the $\mathrm{Cu}$ film. Thus, we found the MOD ink containing $\mathrm{Cu}$ (II)/AmIP/acetate complex could produce $\mathrm{Cu}$ film at $150{ }^{\circ} \mathrm{C}$ due to the reducing ability of AmIP. However, it was difficult to obtain a uniform $\mathrm{Cu}$ film from the MOD ink owing to the formation of many cracks and the in homogeneity. The resultant $\mathrm{Cu}$ film showed high resistivity value with more than $10^{6} \Omega \mathrm{cm}$.

In order to ensure a sufficiently high copper content, hybrid MOD inks were prepared by mixing of metallic $\mathrm{Cu}$ nanoparticles and the MOD ink. The pure copper particlesbased film without the MOD ink showed high resistivity value of more than $10^{6} \Omega \mathrm{cm}$ even after the heating of $180^{\circ} \mathrm{C}$ for 60 min under a $\mathrm{N}_{2}$ gas flow. In contrast, the electrical resistivity of $\mathrm{Cu}$ film after the heating of $180^{\circ} \mathrm{C}$ from the hybrid MOD ink dramatically decreased. The resistivity values were of the order of $10^{-4} \sim 10^{-5} \Omega \mathrm{cm}$, depending on the weight ratio of the $\mathrm{Cu}$ particles to the hybrid MOD ink in the range examined here. The resistivity values were $8.1 \times 10^{-5} \pm 1.3 \times 10^{-5}, 7.3 \times$ $10^{-5} \pm 1.8 \times 10^{-5}, 7.6 \times 10^{-5} \pm 0.5 \times 10^{-5}, 15 \times 10^{-5} \pm 4.5 \times 10^{-5}$, and
$24 \times 10^{-5} \pm 6.5 \times 10^{-5} \Omega \mathrm{cm}$ for weight ratios of $4: 1,3: 1,2: 1$, $1: 1$, and 1:2 Cu particles to MOD ink, respectively (Figure 3 ). The $\mathrm{Cu}$ film with lowest electrical resistivity was obtained from the hybrid MOD ink with a 3:1 ratio of $\mathrm{Cu}$ particles to MOD ink [hybrid MOD ink (3:1)]. The SEM images of the $\mathrm{Cu}$ film obtained from the hybrid MOD ink (3:1) showed closepacked $\mathrm{Cu}$ particles on the surface of the calcined film at the the heating temperature of $180{ }^{\circ} \mathrm{C}$ for 60 min under a $\mathrm{N}_{2}$ gas flow (Figure 4). By adding the MOD ink into $\mathrm{Cu}$ particles, the packing density of $\mathrm{Cu}$ particles and the electric connection were significantly improved, resulting in the low electrical resistivity of $\mathrm{Cu}$ film.

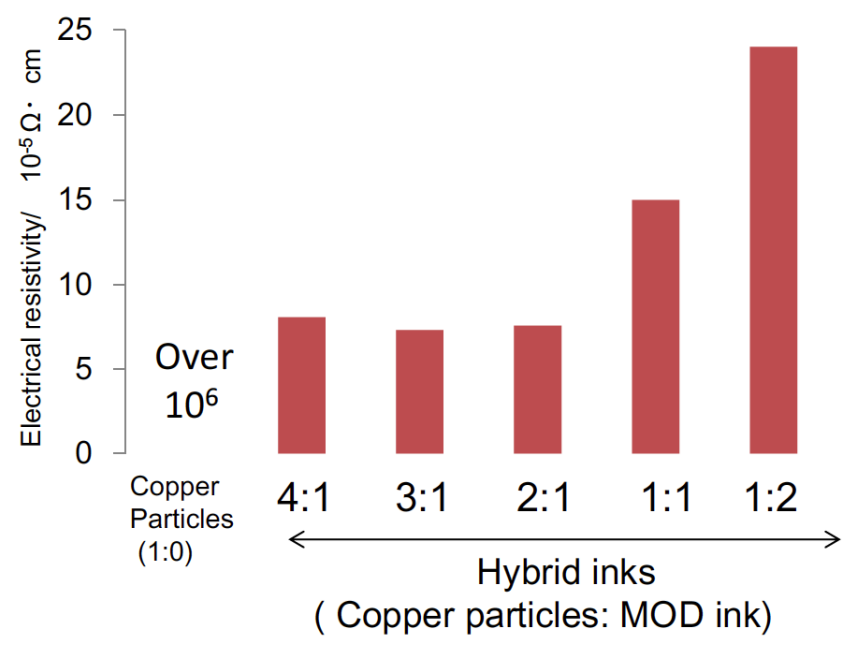

Figure 3: Electrical resistivity of Cu films after thermal sintering of the hybrid MOD inks with different weight ratios of copper particles to MOD ink at $180{ }^{\circ} \mathrm{C}$ for 60 min under a flow of $\mathrm{N}_{2}$.

Figure 5a shows the electrical resistance of the $\mathrm{Cu}$ films prepared from hybrid MOD ink (3:1) sintered at different temperatures between 120 and $250{ }^{\circ} \mathrm{C}$ for 60 min under a $\mathrm{N}_{2}$ gas flow. The electrical resistivity of the $\mathrm{Cu}$ films dramatically decreased between 120 and $150{ }^{\circ} \mathrm{C}$, which is consistent with the thermal decomposition temperature of $\mathrm{Cu}$ (II)-AmIPacetate complex (as shown in Figure 1b). The electrical 
(a)

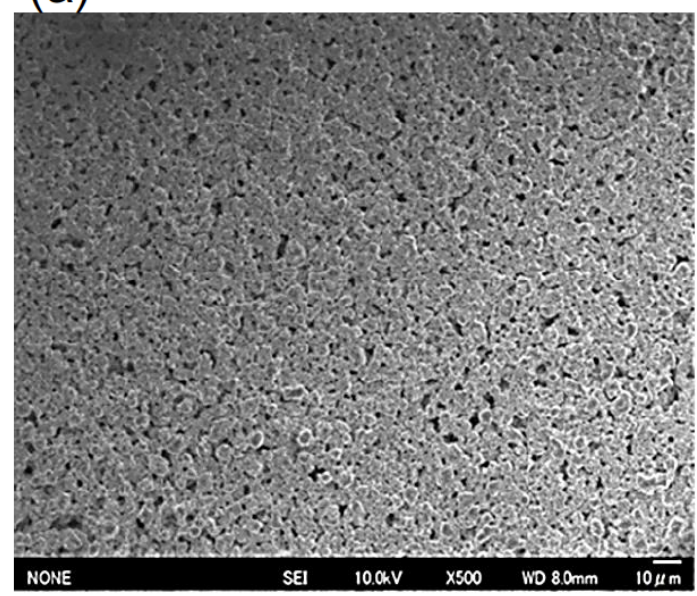

(b)

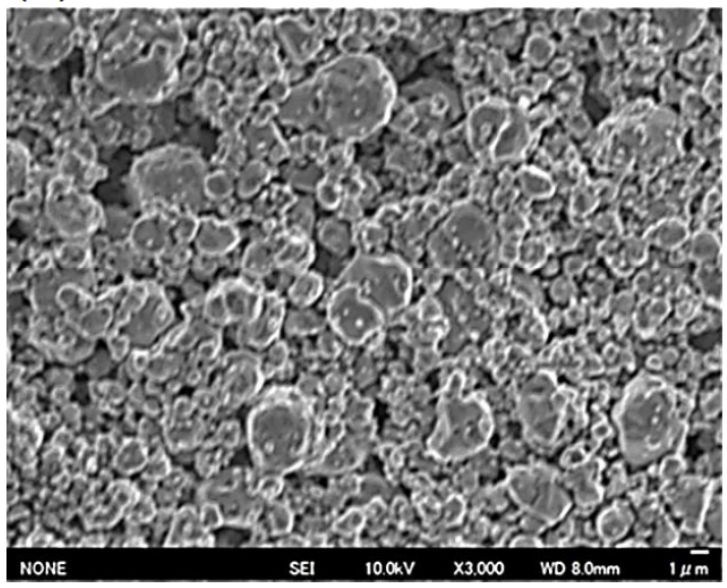

Figure 4: FE-SEM images of a Cu film made from a hybrid MOD ink with a weight ratio of 3:1 (copper particles:MOD ink) on a polyimide film after sintering at $180^{\circ} \mathrm{C}$ for 60 min under $\mathrm{N}_{2}$ flow.
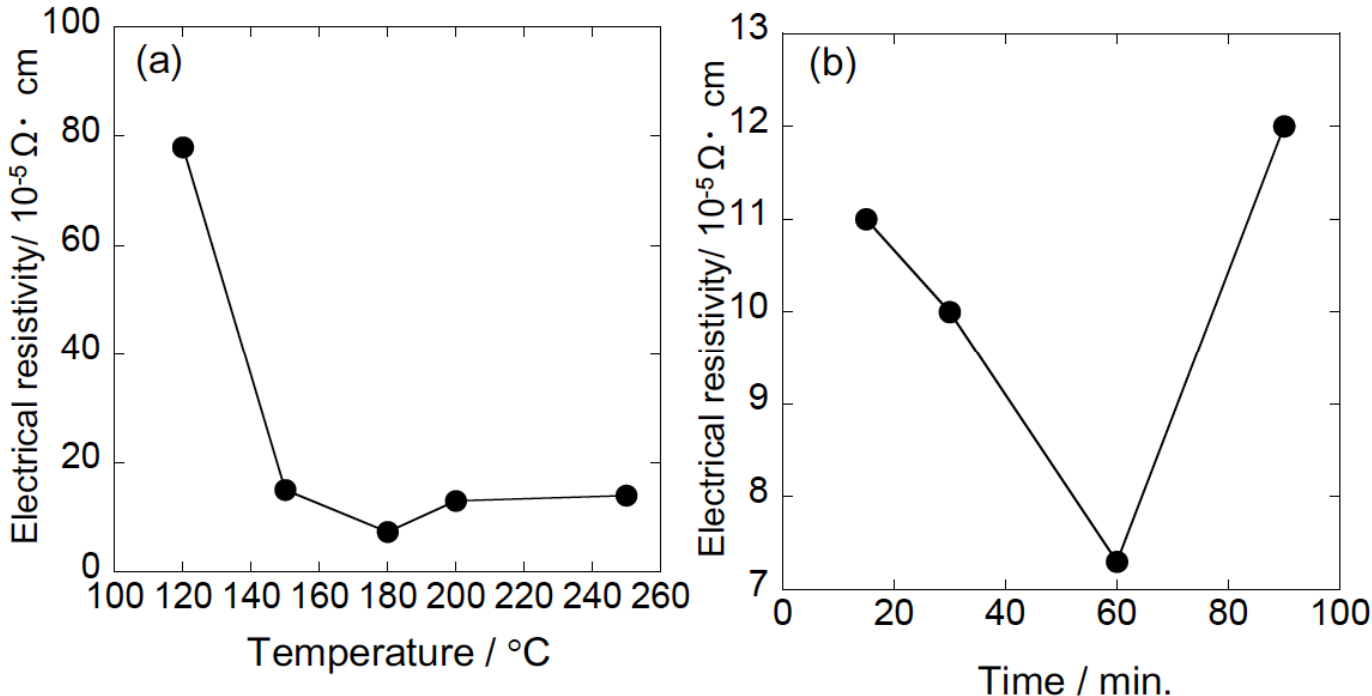

Figure 5: Electrical resistivity of Cu films (prepared from a hybrid MOD ink with a weight ratio of 3:1, copper particles:MOD ink) on polyimide films as a function of (a) sintering temperature (60 min sintering time), and (b) sintering time $\left(180^{\circ} \mathrm{C}\right.$ sintering temperature).

resistivity values decreased further above $120{ }^{\circ} \mathrm{C}$ $\left(78 \times 10^{-5} \pm 15 \times 10^{-5}, \quad 15 \times 10^{-5} \pm 4.5 \times 10^{-5}, \quad\right.$ and7.3 $\times$ $10^{-5} \pm 1.8 \times 10^{-5} \Omega \mathrm{cm}$ at 120,150 , and $180{ }^{\circ} \mathrm{C}$, respectively), and they slightly increased as the heating temperature increased from 180 to $250{ }^{\circ} \mathrm{C} \quad\left(7.3 \times 10^{-5} \pm 1.8 \times 10^{-5}\right.$, $13 \times 10^{-5} \pm 3.5 \times 10^{-5}$, and $14 \times 10^{-5} \pm 2.5 \times 10^{-5} \Omega \mathrm{cm}$ at 180,200 , and $250^{\circ} \mathrm{C}$, respectively). The sintering temperature to obtain the $\mathrm{Cu}$ film with the lowest electrical resistivity from the hybrid MOD ink $(3: 1)$ is $180{ }^{\circ} \mathrm{C}$. The electrical resistivity of the $\mathrm{Cu}$ films depended on the sintering time, as shown in Figure $\mathbf{5 b}$ for the hybrid MOD ink (3:1) sintered at $180{ }^{\circ} \mathrm{C}$. It shold be emphasized that a low electrical resistivity of $11 \times 10^{-5} \Omega \mathrm{cm}$ was achieved at even a short heating time of $15 \mathrm{~min}$, and that the minimum value of $7.3 \times 10^{-5} \Omega \mathrm{cm}$ was obtained after heating for $60 \mathrm{~min}$. Longer times above $60 \mathrm{~min}$ resulted in an increase in the resistivity, which might be due to the oxidation of copper.

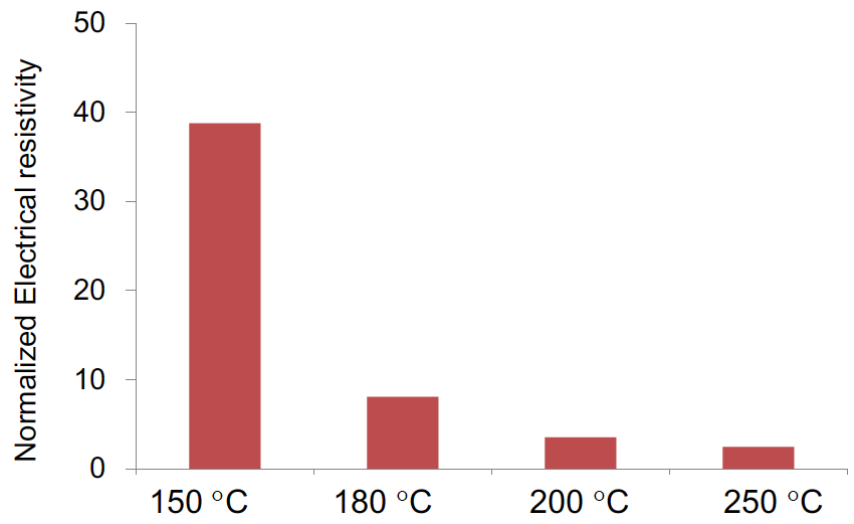

Figure 6: Normalized electrical resistance of Cu films (prepared from a hybrid MOD ink with a weight ratio of $3: 1$, copper particles:MOD ink)sintered at different temperatures after exposure to air and humidity $(30 \pm 5 \%)$ at $23{ }^{\circ} \mathrm{C}$ for two months. The reference resistance was the initial value before this ageing test. 
(a)

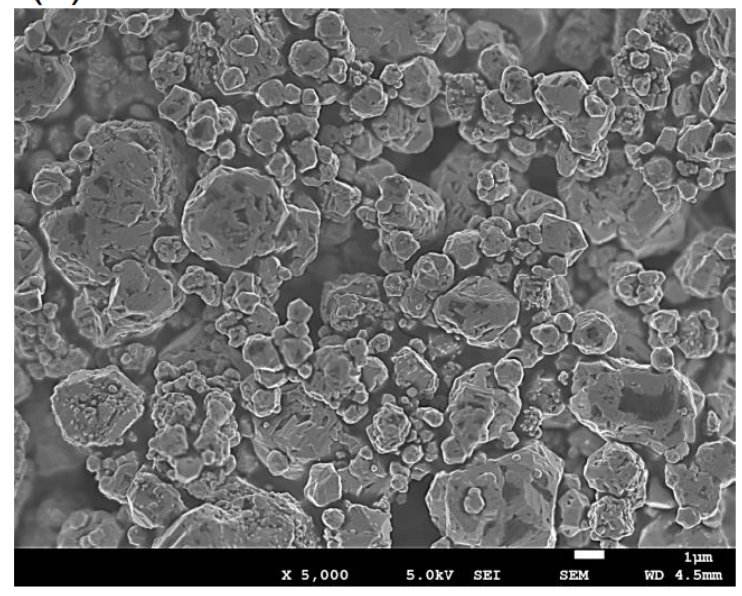

(b)

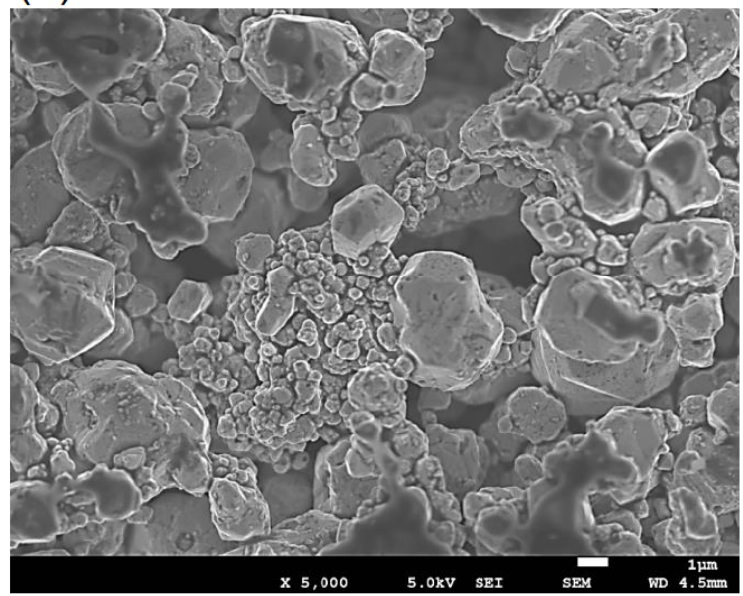

Figure 7: FE-SEM images of a Cu film (prepared from a hybrid MOD ink with a weight ratio of 3:1, copper particles:MOD ink) on a polyimide film after sintering at (a) $150^{\circ} \mathrm{C}$ and (b) $200^{\circ} \mathrm{C}$ for 60 min under $\mathrm{N}_{2}$ flow.

In the present study, we also examined the long-term stability of $\mathrm{Cu}$ films after two months under an air atmosphere at 23 ${ }^{\circ} \mathrm{C}$, which were prepared from the hybrid MOD ink (3:1) (Figure 6). The long-term stability of the $\mathrm{Cu}$ film strongly depended on the sintering temperatures of $\mathrm{Cu}$ films. The increase of $\mathrm{Cu}$ film resistance after two months was observed for the $\mathrm{Cu}$ film obtained from the sintering temperature of 150 ${ }^{\circ} \mathrm{C}$, but it became smaller for the $\mathrm{Cu}$ film heated at higher temperatures of more than $180{ }^{\circ} \mathrm{C}$. A low film resistance of $10^{-4} \Omega \mathrm{cm}$ was kept even after exposure to air for two months at the sintering temperatures of more than $180{ }^{\circ} \mathrm{C}$. It should be noted that the electrical resistivity value of $\mathrm{Cu}$ film obtained from the sintering temperature of $150{ }^{\circ} \mathrm{C}\left(15 \times 10^{-5}\right.$ $\Omega \mathrm{cm})$ was almost identical to that $\left(13 \times 10^{-5} \Omega \mathrm{cm}\right)$ at $200^{\circ} \mathrm{C}$ after the preparation, but the long-term stability of $\mathrm{Cu}$ film prepared at $200{ }^{\circ} \mathrm{C}$ was much higher than that at $150{ }^{\circ} \mathrm{C}$.

The SEM images showed the $\mathrm{Cu}$ (II)-AmIP-acetate complexes are decomposed to form $\mathrm{Cu}$ nanoparticles less than $1 \mu \mathrm{m}$, and they are randomly stacked together with large $\mathrm{Cu}$ particles, as shown in Figure $\mathbf{7 b}$. Moreover, the continuous $\mathrm{Cu}$ films clearly exist on the surface of large $\mathrm{Cu}$ particles. The small $\mathrm{Cu}$ nanoparticles from thermal decomposition of $\mathrm{Cu}$ (II)-AmIP-acetate complexes connect the large $\mathrm{Cu}$ particles together to improve the electrical resistivity and the long-term stability.

\section{CONCLUSIONS}

Highly conductive copper films were achieved at low sintering temperatures using a hybrid MOD ink containing copper particles and $\mathrm{Cu}$ (II)-AmIP-Ac complex. For the first time, high quality copper films could be formed from such inks without requiring formate or a reducing gas as the AmIP successfully reduced the $\mathrm{Cu}$ (II) complex at low temperatures between 120 and $140{ }^{\circ} \mathrm{C}$. The conductive copper film consisted of close-packed copper particles with a low resistance of $7.3 \times 10^{-5} \Omega \mathrm{cm}$ after sintering at $180{ }^{\circ} \mathrm{C}$ for 60 min under a $\mathrm{N}_{2}$ gas flow. Removing formate from the processing would make the use of hybrid MOD inks safer and simpler for fabricating printed electronic devices.

\section{ACKNOWLEDGEMENTS}

We thank Aoi Kodamaat Kansai University for sample preparation about $\mathrm{Cu}$ nanoink. This work was supported by JSPS KAKENHI (Grant No. 15H03520, 15H03526, and 26107719).

\section{REFERENCES}

[1] Wunscher S, Abbel R, Perelaer J, Schubert US. Progress of alternative sintering approaches of inkjet-printed metal inks and their application for manufacturing of flexible electronic devices. J Mater Chem C 2014; 2: 10232-10261. http://dx.doi.org/10.1039/C4TC01820F

[2] Abhinav KV, Rao RVK, Karthika P, Singh SP. Copper conductive inks: synthesis and utilization in flexible electronics. RSC Adv 2015; 5 : 63985-64030.

http://dx.doi.org/10.1039/C5RA08205F

[3] Woo K, Bae C, Jeong Y, Kim D, Moon J. Inkjet-printed Cu source/drain electrodes for solution-deposited thin film transistors. J Mater Chem 2010; 20: 3877-3882.

http://dx.doi.org/10.1039/c000162g

[4] Jeong S, Lee SH, Jo Y, Lee SS, Seo Y, Ahn BW, Kim G, Jang G-E, Park J-U, Ryua B-H, Choi Y. Air-stable, surface-oxide free $\mathrm{Cu}$ nanoparticles for highly conductive $\mathrm{Cu}$ ink and their application to printed graphene transistors. J Mater Chem C 2013; 1: 2704-2710. http://dx.doi.org/10.1039/c3tc00904a

[5] Lee B, Kim Y, Yang S, Jeong I, Moon J. A low-cure-temperature copper nano ink for highly conductive printed electrodes. Curr Appl Phys 2009; 9: e157-e160. http://dx.doi.org/10.1016/j.cap.2009.03.008

[6] Lee YI, Lee KJ, Goo YS, Kim NW, Byun Y, Kim JD, Yoo B, Choa YH. Effect of Complex Agent on Characteristics of Copper Conductive Pattern Formed by Ink-jet Printing. Jpn J Appl Phys 2010; 49: 086501. http://dx.doi.org/10.1143/JJAP.49.086501

[7] Kim SJ, Lee J, Choi YH, Yeon DH, Byun Y. Effect of copper concentration in printable copper inks on film fabrication. Thin Solid Films 2012; 520: 2731-2734.

http://dx.doi.org/10.1016/j.tsf.2011.11.056

[8] Yabuki A, Tanaka S. Electrically conductive copper film prepared at low temperature by thermal decomposition of copper amine complexes with various amines. Mater Res Bull 2012; 47: 4107-4111. http://dx.doi.org/10.1016/j.materresbull.2012.08.052 
[9] Araki T, Sugahara T, Jiu J, Nagao S, Nogi M, Koga H, Uchida H, Shinozaki K, Suganuma K. Cu Salt Ink Formulation for Printed Electronics using Photonic Sintering. Langmuir 2013; 35: 1119211197.

http://dx.doi.org/10.1021/la402026r

[10] Shin $\mathrm{DH}$, Woo S, Yem H, Cha M, Cho S, Kang M, Jeong S, Kim Y Kang K, Piao, Y. A Self-Reducible and Alcohol-Soluble Copper-Based Metal-Organic Decomposition Ink for Printed Electronics. ACS Appl Mater Interfaces 2014; 6: 3312-3319. http://dx.doi.org/10.1021/am4036306

[11] Choi $\mathrm{YH}$, Hong SH. Effect of the Amine Concentration on Phase Evolution and Densification in Printed Films Using Cu(II) Complex Ink. Langmuir 2015; 31: 8101-8110. http://dx.doi.org/10.1021/acs.langmuir.5b01207

[12] Farraj Y, Grouchko M, Magdass S. Self-reduction of a copper complex MOD ink for inkjet printing conductive patterns on plastics. Chem Commun 2015; 51: 1587-1590. http://dx.doi.org/10.1039/C4CC08749F

[13] Deng D, Qi T, Cheng Y, Jin Y, Xiao F. Copper carboxylate with different carbon chain lengths as metal-organic decomposition ink. J Mater Sci Mater Electron 2014; 25: 390-397. http://dx.doi.org/10.1007/s10854-013-1599-y
[14] Adner D, Wolf FM, Möckel S, Perelaer J, Schubert US, Lang H. Copper(II) ethylene glycol carboxylates as precursors for inkjet printing of conductive copper patterns. Thin Solid Films 2014; 565: 143-148. http://dx.doi.org/10.1016/i.tsf.2014.06.054

[15] Yonezawa T, Tsukamoto $\mathrm{H}$, Yong $\mathrm{Y}$, Nguyen MT, Matsubara M. Low temperature sintering process of copper fine particles under nitrogen gas flow with $\mathrm{Cu}^{2+}$-alkanolamine metallacycle compounds for electrically conductive layer formation. RSC Adv 2016; 6: 1204812052.

http://dx.doi.org/10.1039/C5RA25058G

[16] Hokita Y, Kanzaki M, Sugiyama T, Arakawa R, Kawasaki H. HighConcentration Synthesis of Sub-10-nm Copper Nanoparticles for Application to Conductive Nanoinks. ACS Appl Mater Interfaces 2015; 7: 19382-19389. http://dx.doi.org/10.1021/acsami.5b05542

[17] Lin Z, Han D, Li S. Study on thermal decomposition of copper(II) acetatemonohydrate in air. J Therm Anal Calorim 2012; 107: 471-475 http://dx.doi.org/10.1007/s10973-011-1454-4

\section{(C) 2016 Kawasaki et al.; Licensee Lifescience Global.}

This is an open access article licensed under the terms of the Creative Commons Attribution Non-Commercial License (http://creativecommons.org/licenses/by-nc/3.0/) which permits unrestricted, non-commercial use, distribution and reproduction in any medium, provided the work is properly cited. 